Review Article

\title{
Contribution of In Vivo and Organotypic 3D Models to Understanding the Role of Macrophages and Neutrophils in the Pathogenesis of Psoriasis
}

\author{
Isabelle Lorthois, ${ }^{1,2}$ Daniel Asselineau, ${ }^{3}$ Nathalie Seyler, ${ }^{4}$ and Roxane Pouliot ${ }^{1,2}$ \\ ${ }^{1}$ Centre LOEX de l'Université Laval, Génie Tissulaire et Régénération, Centre de Recherche FRQS du CHU de Québec, \\ Axe Médecine Régénératrice, Québec, QC, Canada \\ ${ }^{2}$ Faculté de Pharmacie, Université Laval, Québec, QC, Canada \\ ${ }^{3}$ L'Oréal Research \& Innovation, Aulnay-sous-Bois, France \\ ${ }^{4}$ Episkin Academy, Lyon, France
}

Correspondence should be addressed to Roxane Pouliot; roxane.pouliot@pha.ulaval.ca

Received 19 May 2017; Revised 15 September 2017; Accepted 2 October 2017; Published 8 November 2017

Academic Editor: Anna Balato

Copyright (C) 2017 Isabelle Lorthois et al. This is an open access article distributed under the Creative Commons Attribution License, which permits unrestricted use, distribution, and reproduction in any medium, provided the original work is properly cited.

\begin{abstract}
Psoriasis, a common chronic immune-mediated skin disease, is histologically characterized by a rapid keratinocyte turnover and differentiation defects. Key insights favor the idea that $\mathrm{T}$ cells are not the only key actors involved in the inflammatory process. Innate immune cells, more precisely neutrophils and macrophages, provide specific signals involved in the initiation and the maintenance of the pathogenesis. Current data from animal models and, to a lesser extent, three-dimensional in vitro models have confirmed the interest in leaning towards other immune cell types as a potential new cellular target for the treatment of the disease. Although these models do not mimic the complex phenotype nor all human features of psoriasis, their development is necessary and essential to better understand reciprocal interactions between skin cells and innate immune cells and to emphasize the crucial importance of the local lesional microenvironment. In this review, through the use of in vivo and 3D organotypic models, we aim to shed light on the crosstalk between epithelial and immune components and to discuss the role of secreted inflammatory molecules in the development of this chronic skin disease.
\end{abstract}

\section{Introduction}

Psoriasis is a chronic autoimmune disease that affects $2-3 \%$ of the world's population, characterized by hyperproliferation and abnormal differentiation of epidermal keratinocytes [1-6]. Psoriatic skin lesions are also characterized by increased permeability of lymphatic capillaries, increased blood flow, and angioproliferation [7-10]. Eighty percent of patients suffer from mild to moderate forms of the disease, while $20 \%$ of patients develop moderate to severe psoriasis, affecting more than $5 \%$ of their body surface area [11]. It is also known that patients with plaque psoriasis have an increased risk of inflammatory diseases affecting noncutaneous sites-including psoriatic arthritis, cardiovascular disease, and inflammatory bowel disease-associated with common pathophysiological mechanisms. These comorbidities are multifactorial and in many cases related to inflammation, induced by close pathogenic mechanisms related to cytokine dysregulation.

PSORS1 is the major susceptibility locus for psoriasis vulgaris and lies within an approximately $300 \mathrm{~kb}$ segment of the major histocompatibility complex on chromosome 6 p21.3 [12-14]. Several studies have indicated HLA-Cw6 as the primary PSORS1 risk allele within the candidate region, coherent with the fact that MHC class I molecules play an important role in the function of $\mathrm{CD}^{+} \mathrm{T}$ cells $[15,16]$.

More than 32 PSORS have been identified, containing genes involved in inflammatory metabolic pathways and epidermal proliferation as well as skin barrier function, but have not demonstrated their complete involvement in 
pathology. Also, the variations in the number of copies of a gene may be involved in the pathology. For example, beta defensins, antimicrobial peptides involved in innate immunity, are a good example of a gene known to be associated with psoriasis. Of the 8 defensins, the hBD-2, hBD-3, and hBD-4 proteins encoded, respectively, by DEFB2, DEFB3, and DEFB4 were linked to keratinocyte stimulation via proinflammatory interleukins 8,18 , and 20 [17]. The eight defensin genes are linked on two different chromosomes, chromosome 20 as well as chromosome 8 p23.1. Most of the defensin genes encoded on chromosome 8p23.1 have longer gene repeat units, which are highly variable in copy number. Several studies have attributed a relationship between psoriasis and the number of gene copies of these defensins [18]. In 2012, a meta-GWAS (genome-wide association studies), which aims to identify SNPs (single nucleotide polymorphisms) in DNA associated with a clinically defined disease (phenotype) by comparing the allele frequency of each SNP between a group of individuals with psoriasis versus healthy patients, confirmed 21 SNPs, and identified 15 new SNPs [19].

The current research tends to demonstrate that the process is initiated by an inflammatory immune reaction against autoantigens of the skin, in which dendritic cells, $\mathrm{T}$ lymphocytes, macrophages, and neutrophils play a pivotal role. Dendritic cells, antigen-presenting cells, are present in greater numbers in psoriatic lesions. Dendritic cells of lymphoid origin, such as plasmacytoid dendritic cells, would be involved in initiating lesions [20], recognizing autoantigens, and causing IFN- $\alpha$ secretion by these cells [21]. This would follow the activation of innate immunity cells, such as neutrophils or macrophages, and adaptive immune cells, such as T lymphocytes. Persistent activation of these cells would lead to the chronicization of psoriatic lesions, such as a vicious circle of inflammation $[2,22,23]$.

Resident macrophages and dendritic cells are among the cells most involved in the "sensing" of danger signals. The activation of macrophages via the secretion of proinflammatory cytokines, such as IL- 6 and TNF- $\alpha$, but also of chemokines, such as CXCL8 (also known as IL-8), CCL5, CXCL1, and CXCL2, promotes the recruitment of inflammatory cells, like neutrophils [24]. Multiple signals are likely to trigger, via interaction with their receptor(s), a secretion of chemokines, thus attracting neutrophils to the inflammatory site. Macrophages and neutrophils may act as $\mathrm{T}$ lymphocyte-dependent effectors, as they are present at the site of inflammation even before a specific immune response has developed.

It is therefore evident that monocytes, macrophages, and neutrophils have a particular function in the early phases of inflammation, and their role in driving and maintaining this inflammatory process in the pathogenesis of psoriasis must be clarified. Here, we aim to discuss the specific role of innate immune cells, such as neutrophils and macrophages, in the initiation and the sustainability of chronic inflammatory skin diseases, such as psoriasis, through the use of organotypic models and mouse models. These models allow a better understanding of cellular and molecular mechanisms with the aim of identifying new potential therapeutic targets.

\section{Macrophages}

Monocytes can differentiate to become tissue-resident macrophages or dendritic cells. Macrophages are phagocytic cells [25] within the dermis, important for tissue homeostasis and the regulation of lymphocyte activation and proliferation [26]. Some macrophages are long-term tissue residents and play an important role in controlling the repair $[27,28]$ and regeneration of skin tissue [29]. Inflammatory macrophages, on the other hand, participate in the innate immune response and play a dual role in the immune system as phagocytes and antigen-presenting cells capable of activating $\mathrm{T}$ lymphocytes (Figure 1).

As early as the 1980s, some evidence of increased macrophage activity in psoriasis [30] highlights their key role in inducing psoriasis-like skin disease.

In 2010, Fuentes-Duculan and colleagues observed that a subpopulation of CD163-positive macrophages was found mostly in psoriatic lesions. The CD163 marker, a scavenger receptor intervening in the elimination of the hemoglobinhaptoglobin complex, expressed both on the surface of the mature tissue macrophages and on blood monocytes, is in normal human skin, a marker more assimilated to the socalled "alternative" macrophages or M2 [31]. However, CD163-positive macrophages also express IFN- $\gamma$-regulated genes (STAT1, CXCL9), and IFN- $\gamma$ is known to be a "type 1 cytokine." These results suggest a great phenotypic plasticity of the macrophages in responding to their environment and acquiring new properties and new markers, while preserving their original characteristics.

Other macrophage markers such as RFD7 [32], CD68 [33, 34], CD107 [35, 36], MARCO [37], Stabilin-1 [38], and MS-1 $[39,40]$ are not generally expressed at the same time on their surface, but their expression fluctuates according to their location in the skin compartments. For example, CD68 ${ }^{+}$cells coexpress CD163 in the upper reticular dermis while they do not colocalize with CD163 near the dermoepidermal junction. It has also been shown that these markers coexpress to some extent CD11c, a marker of myeloid dendritic cells, but CD163 has the weakest coexpression with $\mathrm{CD} 11 \mathrm{c}$, an ideal candidate for labeling macrophages in psoriasis [31]. The cutaneous macrophages of lesional plaques probably do not have a single phenotype, M1, or M2 but rather have a mixed, microenvironment-dependent phenotype, associated with the different roles they can play in a context of chronic inflammation.

Egawa et al. have also demonstrated that CCR2 ${ }^{+}$monocytes recruited at inflammatory sites had the potential to acquire an M2 phenotype in response to IL-4, thus exerting an anti-inflammatory function [41], while the expression of CCR2 (MCP-1/CCL2 protein receptor) of the peripheral monocytes of patients with psoriasis or atopic dermatitis was increased compared to that of healthy patients [42]. It has also been demonstrated that macrophages M1 or M2 have the ability to be repolarized by the cytokines of Th2 or Th1 lymphocytes, respectively [43].

The hypomorphic PL/J CD18 murine model is characterized by reduced expression (2-16\% of the wild-type levels) of the common integrin 2 (CD11/CD18) chain, 


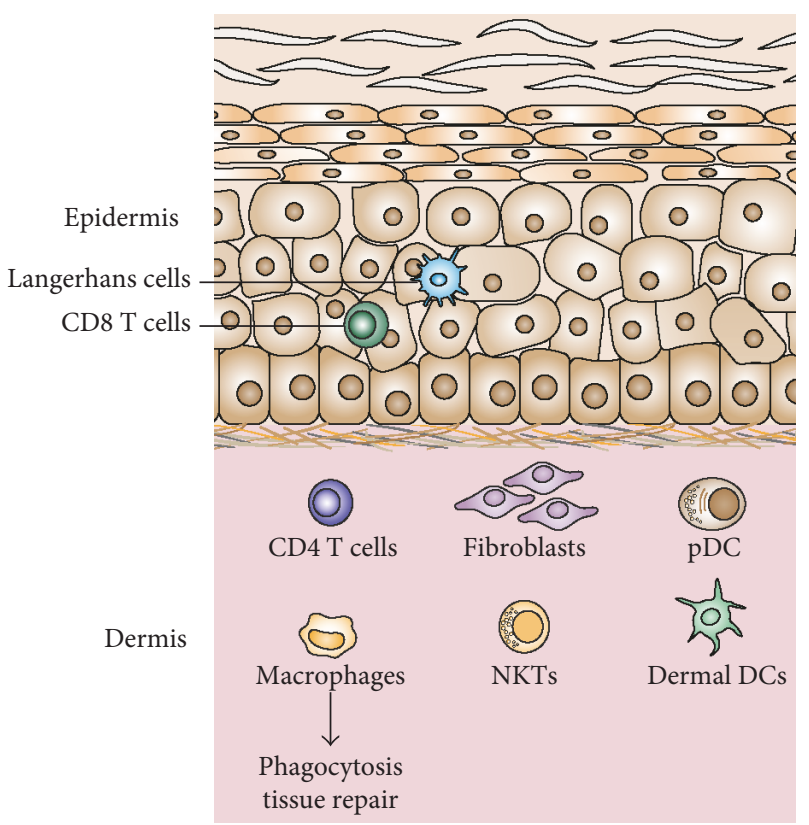

(a)

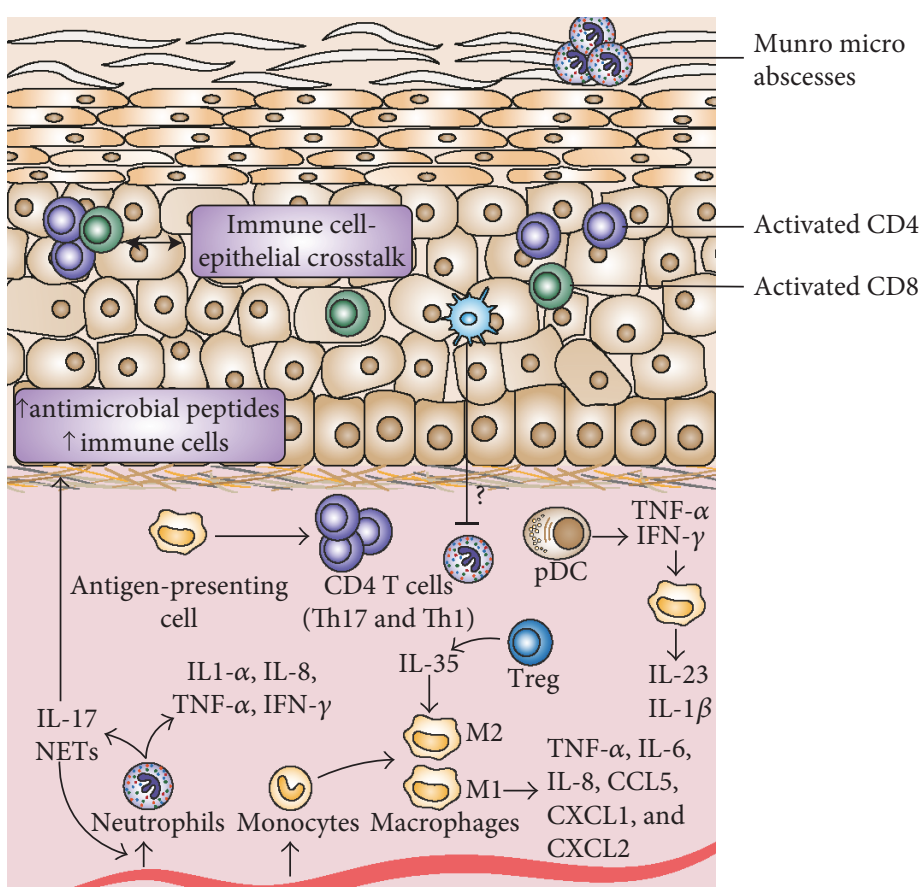

(b)

FIGURE 1: Location and function of macrophages and neutrophils in healthy (a) and psoriatic (b) skin. Langerhans cells and CD8 T cells are present in healthy epidermis, while CD4 T cells, as well as macrophages, NK T cells, dermal dendritic cells (DCs), and plasmacytoid dendritic cells (pDCs), are found in the dermis mainly composed by fibroblasts and extracellular matrix. Immune cell infiltrates are present in the psoriatic epidermis, consisting of activated CD4 and CD8 T cells and clusters of Munro's abscess in the stratum corneum. In the dermis, the activation of cells of both innate and adaptive promotes an inflammatory response. Neutrophils and macrophages (differentiated from monocytes) infiltrate the dermis and secrete proinflammatory cytokines. The crosstalk between skin cells and immune cells leads to a complex inflammatory response and contributes to the development of a pathological epithelial phenotype. NET: neutrophil extracellular trap; Treg: regulatory T cell; M: macrophage.

leukocyte adhesion molecules required for cell-cell contacts. Transgenic mice generally develop psoriasiform skin inflammation: erythema, scaling, abnormal keratinocyte proliferation/differentiation, subcorneal microabscesses, and increased inflammatory infiltrate. The authors reported that the activation of cutaneous macrophages by recombinant MCP-1 or LPS alone was not sufficient to produce chronic psoriasis-like inflammation as observed in vivo in human skin lesions [44]. Nevertheless, the combined injection of recombinant murine MCP-1 and TNF- $\alpha$ in nonlesional skin area of hypomorphic CD18 mice led, respectively, to the accumulation and activation of macrophages, unlike CD4positive T cells. Activated macrophages would secrete more TNF- $\alpha$, responsible for sustained activation of macrophages, thus causing a positive feedback loop. T cells, mast cells, and endothelial cells would participate directly in the chronicization of lesions via TNF- $\alpha$ secretion. Finally, depletion of skin macrophages in this murine model via the injection of clodronate liposomes (specific depletion of macrophages) and the neutralization of a single cytokine, TNF- $\alpha$, attenuates the severity of skin inflammation, emphasizing the importance of macrophages in the psoriasis physiopathology.

A specific deletion of the keratinocyte NF- $\kappa \mathrm{B}$ kinase inhibitor (IKK2) in mice results in an inflammatory and hyperproliferative cutaneous phenotype. The treatment of transgenic mice with a TNF-neutralizing antibody abolished the inflammatory phenotype and therefore improved the skin phenotype. The injection of clodronate liposomes in this murine model restored the expression of early and late keratinocyte differentiation markers and reduced the number of granulocytes and $\mathrm{T}$ cells present, highlighting the importance of macrophages in the accumulation of granulocytes and $\mathrm{T}$ cells in inflammatory skin areas [45]. Moreover, a K14Cre-IKK2 $2^{\mathrm{fl} / \mathrm{fl}}$ murine model showed the upward expression of gene coding for proteins regulated by IFN- $\gamma$. The presence of IFN- $\gamma$ receptor may accelerate the onset of the psoriasislike inflammatory skin disease in K14-Cre-IKK2 ${ }^{\mathrm{fl} / \mathrm{fl}}$ mice but is not essential for it to develop. The authors demonstrated that the migration of macrophages to the lesional skin areas and their subsequent activation was a necessary key feature for the development of psoriatic inflammation. The activated macrophages were then able to initiate and maintain psoriasiform skin inflammation. These investigations were also commented in the Journal of Clinical Investigation by Clark and Kupper in 2006 [46].

The topical application model of imiquimod (IMQ), a 7/8 TLR (toll-like receptor) agonist widely used in mice, activated immune cells, such as macrophages and plasmacytoid dendritic cells. The mice displayed a hyperplastic cutaneous epithelial-squamous phenotype similar to human psoriasis. Imiquimod-treated mice, $\mathrm{KO}$ for CX3CR1 (fractalkine/CX3CL1 receptor), developed minor inflammation 
compared to WT mice. In fact, the production of IL-12, IL-23, IL-17A, IL-22, IL-6, IL-1, TNF- $\alpha$, and IL-36 cytokines was decreased in these mice. The macrophages of CX3CR1 ${ }^{-/-}$ mice expressed CCR2, unlike WT mice treated with IMQ, and attenuated the inflammation generated, in part, by Th1/Th17 lymphocytes, following functional changes [47]. The authors hypothesized that CCR2 could partially compensate for the loss of CX3CR1 by directing the migration of resident macrophages. Surprisingly, CCR $2^{-1-}$ mice exhibited an exacerbation of inflammation despite altered recruitment of inflammatory monocytes to cutaneous sites. CX3CR1 $1^{-1-}$ mice expressed fewer M1 macrophage markers compared to WT mice, suggesting that decreasing the number of M1 macrophages would contribute to decreased inflammation resulting from CX3CR1 deficiency. Finally, a transfer of macrophages from WT mice to CX3CR1 $1^{-1-}$ mice normalized psoriasiform type inflammation induced by IMQ, emphasizing the importance of macrophages in the regulation of psoriatic inflammation.

The KC-Tie2-overexpressing mice developed a cutaneous psoriasiform phenotype. These mice spontaneously developed characteristic hallmarks of human psoriasis, including acanthosis (hyperplasia of the epidermis), increases in dermal $\mathrm{CD}^{+} \mathrm{T}$ cells, infiltrating epidermal $\mathrm{CD}^{+} \mathrm{T}$ cells, dermal dendritic cells and macrophages, and increased expression of cytokines and chemokines associated with psoriasis (IFN- $\gamma$, TNF- $\alpha$, IL- $1 \alpha$, IL-6, IL-12, IL-22, IL-23, and IL-17). Cathelicidin, $\beta$-defensin, and S100A8/A9 were also upregulated in the hyperproliferative skin [48].

The administration of clodronate liposomes in the skin of transgenic KC-Tie2 mice resulted in the elimination of $\mathrm{F} 4 / 80^{+}$macrophages, $\mathrm{CD} 11 \mathrm{~b}^{+}$myeloid cells, and $\mathrm{CD} 11 \mathrm{C}^{+}$ dendritic cells. The eradication of these cells would result in the disappearance of acanthosis, a decrease in the number of $\mathrm{T}$ cells, and a significant reduction in the production of TNF- $\alpha$, IL-23, IL-1, IL-6, and S1008/9, stressing the importance of myeloid cells and their cytokines in maintaining the pathology [49].

The use of murine models, in particular the topical application of imiquimod in mice, makes it possible to mimic the dominance of monocytes, neutrophils, and dendritic cells derived from monocytes at an early lesion stage, and later, the decreased number of neutrophils and monocytes and the parallel increase in the number of dermal macrophages and Langerhans cells [50], which are then depleted. Langerhans cells are found mainly in the spinous layer of the epidermis. It is estimated that they constitute 2 to $4 \%$ of the epidermal cell population [51]. Derived from the bone marrow, they are transported by the blood to the epidermis [52]. After capturing the outer antigens, they migrate to the lymph nodes where they will initiate a specific immune response by displaying these antigens to the $\mathrm{T}$ lymphocytes. Langerhans cells are therefore antigen-presenting cells [52]. Similarly, in the murine DKO model, whose Jun and JunB transcription factors were deleted, resulting in psoriasiform type inflammation, the increase in the number of Langerhans cells (LCs) by proliferation followed by their subsequent decrease would reproduce the presence of proliferative Langerhans cells in a human lesional context [53]. In this model, the authors indicated that LCs would exert an immunoregulatory role by increasing the expression of IL-10 and PD-L1. Without LCs, the absence of regulatory signals would result in increased skin inflammation in these mice. The depletion of LCs did not alter the number of regulatory $\mathrm{T}$ cells in the skin, thus excluding the possibility that a reduced number of regulatory $\mathrm{T}$ cells could be responsible for worsening of the pathology. In addition, genetic depletion of LCs during the inflammatory phase in mice treated with imiquimod caused increased neutrophil infiltration and extension of pustular plaques, suggesting an anti-inflammatory role for LCs during psoriatic inflammation [50].

Recently, Leite Dantas et al. focused on the contribution of macrophages and $\mathrm{T}$ cells in the development of psoriasiform inflammation in a transgenic mouse model ihTNFtg (doxycycline- [Dox-] inducible human TNF-transgenic mouse line). In this murine model, the authors found that only macrophages (M1 and M2), Th1, and Treg were present in large quantities. While depletion of macrophages greatly reduced the development of the disease, Treg depletion increased the infiltration of macrophages into psoriatic inflammatory areas, contributing to the worsening of the pathology. Adoptive transfer of Treg in RAG-1-deficient mice, without either mature B or T lymphocytes, or immunocompetent mice induced the opposite effect, attenuation of symptoms. Thus, Tregs would limit migration of macrophages to injured areas, thereby reducing the harmful effect on tissue of macrophages in these transgenic mice [54].

Recently, IL-35, produced by regulatory T cells, demonstrated immunosuppressive effects in mouse models of psoriasis. Indeed, IL-35 may reduce the local infiltration of macrophages by reducing the levels of cutaneous expression of the macrophages M1 while conversely increasing M2 macrophages. Also, IL-35 may regulate the production of proinflammatory $\mathrm{CD} 4^{+} \mathrm{T}$ cell cytokines and may decrease local lymphocytic infiltration of Th17 cells in K14-VEGF$\mathrm{A}-\mathrm{Tg}$ mice and in mouse models of imiquimod-induced psoriasis [55]. IL-37, expressed in macrophages, epithelial cells, and effector-memory cells, likewise demonstrated an immunosuppressive role in K14-VEGF-A transgenic mice by downregulating the production of proinflammatory cytokines, such as CXCL8, IL-6, and S100A7 [56]. IL-37 acted as a negative feedback inhibitor of inflammatory responses as the reduction of IL-37 protein synthesis in PBMCs with specific siRNA increased the production of several proinflammatory mediators [57] (Table 1).

\section{Neutrophils}

Polymorphonuclear neutrophils (PMNs), or leukocytes, are phagocytic cells characterized by a segmented lobular nucleus and cytoplasmic granules filled with degradation enzymes. PMNs are the most abundant circulating white blood cells and are the first type of cells involved in acute inflammatory reactions to bacterial infections [58]. These phagocytes ingest the microbes and release reactive oxygen species, antimicrobial peptides, proteases, and neutrophil extracellular traps [59, 60]. 
TABLE 1: The role of macrophages and neutrophils in different mouse models of psoriasis or other immune diseases.

\begin{tabular}{|c|c|c|c|c|c|}
\hline In vivo models & Mouse model & Phenotype & $\begin{array}{l}\text { Histopathological } \\
\text { hallmarks }\end{array}$ & $\begin{array}{c}\text { Role of } \\
\text { macrophages }\end{array}$ & Role of neutrophils \\
\hline Schon et al. [61] & Flaky skin & Psoriasiform skin lesions & $\begin{array}{l}\text { Prominent infiltrate of } \\
\text { neutrophils, and } \\
\text { microabscesses within the } \\
\text { hyperproliferative } \\
\text { epidermis, hyperkeratosis, } \\
\text { mixed inflammatory } \\
\text { immune infiltrate }\end{array}$ & $\mathrm{x}$ & Yes \\
\hline Wang et al. [44] & $\begin{array}{l}\text { Hypomorphic PL/J } \\
\text { CD18 }\end{array}$ & $\begin{array}{l}\text { Psoriasis-like skin } \\
\text { inflammation }\end{array}$ & $\begin{array}{l}\text { Abnormal keratinocyte } \\
\text { proliferation/ } \\
\text { differentiation, subcorneal } \\
\text { microabscesses, increased } \\
\text { inflammatory infiltrate }\end{array}$ & Yes & $\begin{array}{l}\text { Not causal for the } \\
\text { maintenance of the } \\
\text { skin inflammation }\end{array}$ \\
\hline Stratis et al. [45] & K14-Cre-IKK2fl/fl & $\begin{array}{l}\text { Inflammatory and } \\
\text { hyperproliferative } \\
\text { cutaneous phenotype }\end{array}$ & $\begin{array}{l}\text { Hyperplastic epidermis } \\
\text { with loss of the granular } \\
\text { layer, focal parakeratosis, } \\
\text { infiltration of the dermis } \\
\text { with macrophages, T cells, } \\
\text { mast cells, granulocytes } \\
\text { and microabscesses }\end{array}$ & Yes & $\begin{array}{l}\text { Not required for the } \\
\text { development of the } \\
\text { disease }\end{array}$ \\
\hline Ward et al. [49] & KC-Tie2 & $\begin{array}{c}\text { Cutaneous psoriasiform } \\
\text { phenotype }\end{array}$ & $\begin{array}{l}\text { Acanthosis, increased } \\
\text { CD4-positive T cells, } \\
\text { epidermal CD8-positive T } \\
\text { cells, dermal dendritic cells } \\
\text { and macrophages }\end{array}$ & Yes & $\mathrm{x}$ \\
\hline Sumida et al. [72] & $\begin{array}{l}\text { Topical application } \\
\text { model of imiquimod }\end{array}$ & $\begin{array}{c}\text { Hyperplastic cutaneous } \\
\text { epithelial-squamous } \\
\text { phenotype }\end{array}$ & $\begin{array}{l}\text { Epidermal proliferation, } \\
\text { abnormal differentiation, } \\
\text { epidermal accumulation of } \\
\text { neutrophils in } \\
\text { microabcesses, } \\
\text { neoangiogenesis and } \\
\text { infiltrates of immune cells }\end{array}$ & $\mathrm{x}$ & Yes \\
\hline Keijsers et al. [69] & $\begin{array}{l}\text { Leukotriene } \\
\text { application Tape- } \\
\text { stripping }\end{array}$ & $\begin{array}{c}\text { Skin inflammation } \\
\text { in vivo associated with } \\
\text { the histopathology of } \\
\text { psoriasis }\end{array}$ & $\begin{array}{l}\text { Epidermal proliferation, } \\
\text { influx of } \\
\text { polymorphonuclear cells } \\
\text { in the epidermis and } \\
\text { dermis, followed by a } \\
\text { mononuclear cell infiltrate }\end{array}$ & $\mathrm{x}$ & Yes \\
\hline $\begin{array}{l}\text { Leite Dantas } \\
\text { et al. [54] }\end{array}$ & $\begin{array}{c}\text { Doxycycline- } \\
\text { inducible human } \\
\text { TNF } \alpha \text {-transgenic } \\
\text { mouse }\end{array}$ & $\begin{array}{l}\text { Inflammatory arthritis } \\
\text { and psoriasis-like } \\
\text { phenotype }\end{array}$ & $\begin{array}{l}\text { Hyperproliferation and } \\
\text { aberrant activation of } \\
\text { keratinocytes, infiltration } \\
\text { with Th1, Treg } \\
\text { lymphocytes and } \\
\text { macrophages }\end{array}$ & Yes & $\mathrm{x}$ \\
\hline $\begin{array}{l}\text { Morimura } \\
\text { et al. [47] }\end{array}$ & $\begin{array}{c}\text { Topical application } \\
\text { model of imiquimod } \\
\text { in CX3CR1-deficient } \\
\text { mouse }\end{array}$ & $\begin{array}{c}\text { Hyperplastic cutaneous } \\
\text { epithelial-squamous } \\
\text { phenotype }\end{array}$ & $\begin{array}{l}\text { Epidermal proliferation, } \\
\text { abnormal differentiation, } \\
\text { epidermal accumulation of } \\
\text { neutrophils in } \\
\text { microabcesses, } \\
\text { neoangiogenesis and } \\
\text { infiltrates of immune cells }\end{array}$ & Yes & $\mathrm{x}$ \\
\hline Zhang et al. [55] & $\begin{array}{l}\text { K14-VEGF-A- } \\
\text { transgenic mouse }\end{array}$ & $\begin{array}{l}\text { Psoriasis-like chronic } \\
\text { inflammatory skin } \\
\text { disease }\end{array}$ & $\begin{array}{l}\text { Epidermal hyperplasia, } \\
\text { impaired epidermal } \\
\text { differentiation, } \\
\text { accumulation of dermal } \\
\text { CD4 lymphocytes and } \\
\text { epidermal CD8 } \\
\text { lymphocytes }\end{array}$ & Yes & $\mathrm{x}$ \\
\hline
\end{tabular}


Neutrophils infiltrate psoriatic lesions early from blood vessels within the dermis and form microabscesses, called Munro abscesses in humans, due to their accumulation in the form of microbial clusters in the thickened and parakeratotic stratum corneum [61] (Figure 1). Neutrophils accumulate in the skin, attracted by a gradient of chemotactic factors, which may be small induced secreted cytokines, such as IL-8, NAP-2, and NAP-3; membrane lipid derivatives such as leukotriene and platelet-activating factor (PAF); or substances of bacterial origin (LPS) [62-65].

Schon et al. noted that neutrophil depletion in the flaky skin (fsn)/fsn mutant mouse model of psoriasis-like lesion development contributed to a decrease in epidermal thickness, neutrophilic infiltrate, epidermal microabscesses, and the number of CD3-positive T cells, thus to an improvement of psoriasiform skin lesions [61].

Extravasation of neutrophils was made possible by the binding of integrin $\alpha_{\mathrm{M}} \beta_{2}$ (CD11b/CD18) to ICAM-1 (CD54) of endothelial cells. ICAM-1 would be expressed de novo on the surface of hyperproliferative psoriatic keratinocytes, thus contributing to the migration of neutrophils expressing $\alpha_{\mathrm{M}} \beta_{2}$ to the epidermis [61].

Some neutrophil-derived $\mathrm{T}$ cell attractants, such as defensin-1, defensin-2, or CAP37/azurocidin [66], may explain the reduction in the number of tissue $\mathrm{T}$ lymphocytes upon in vivo depletion of neutrophils in SCID mice. However, the influx of neutrophils into the epidermal compartment via chemoattractants seems to follow the influx of lymphocytes.

Moreover, the depletion of neutrophils in patients with moderate to severe generalized pustular psoriasis via an extracorporeal circulation therapy that selectively eliminates elevated myeloid lineage leukocytes resulted in a decrease in erythroderma, pustules, and edema up to 10 weeks after therapy [67].

Neutrophils would represent a major source of IL-17 [68-70], via the formation of extracellular traps [71], whose production is defined as the ultimate stage in a process of neutrophil polymorphonuclear activation. The topical application of leukotriene B4 (LTB4), found in high concentrations in psoriatic lesions, is a chemoattractant for neutrophils, eosinophils, monocytes, macrophages, mast cells, dendritic cells, and effector T cells. LTB4 induced a rapid influx of polymorphonuclear cells into the epidermis and dermis, followed by an infiltrate of mononuclear cells [69]. Moreover, a recent study has demonstrated that LTB4 receptor 1 (BLT1) and CXCR2 promoted the recruitment of neutrophils at psoriatic lesional sites and that these cells would secrete IL-1 $\beta$, perpetuating psoriatic inflammation [72] (Table 1).

Moreover, the release of this mediator, IL-17, by NETosis amplified the accumulation of neutrophils [73] by increasing the expression of CXCL1, CXCL2, and IL-8. IL-17 increased the expression of antimicrobial peptides- $\beta$-defensin- 2 (HBD-2), S100A7, S100A8, S100A9, and LL37-by keratinocytes [74-76]. These antimicrobial peptides can stimulate immune cell infiltration, and NET-derived DNA-LL37 nucleic acid complexes promoted IFN- $\alpha$ secretion of plasmacytoid dendritic cells [21]. IFN- $\alpha$ and TNF- $\alpha$ would stimulate the influx of inflammatory dendritic cells and macrophages, which would produce cytokines, including IL-23 and IL-1 $\beta$, in the presence of IFN- $\gamma$.

Blocking IL-17A via a neutralizing antibody (secukinumab) reduced hyperkeratosis, acanthosis, and hyperproliferation, significantly decreased the levels of gene expression of chemokines derived from keratinocytes, such as CXCL1 (GRO) and CXCL8 (IL-8), and triggered neartotal elimination of IL-17-positive epidermal neutrophils. The authors suggested that the inhibition of IL-17A would indirectly block the influx of neutrophils due to the lack of keratinocyte response to IL-17A [70].

Furthermore, the specific deletion of the A-chain of IL-17 receptor in mice contributed to the delay and attenuation of psoriatic inflammation in mice treated with imiquimod but did not prevent its development. KO mice for IL-17RA showed a delay and alteration of peripheral neutrophils at the site of injury. The authors hypothesized that IL-6, strongly expressed in KO mice for IL-17RA and treated with imiquimod, may play a role in the development of pathology in the absence of IL-17RA [77]. Nevertheless, there is no doubt that compensatory mechanisms ensure the attraction of neutrophils to the inflammatory site in the absence of the IL-17RA signaling pathway.

The importance of IL- 6 has also been demonstrated in a murine model in which IL-17A and GFP are coexpressed in keratinocytes, resulting in the formation of psoriatic-like lesions. A blockage of IL-6 signaling would reduce the pathology in these mice by reducing the formation of neutrophil microabscesses in the epidermis and reducing the number of myeloperoxidase-positive cells [78].

In 2011, Garcia-Romo et al. reported that NETs would produce a greater amount of LL37 in response to PMA and IFN- $\gamma$ in systemic lupus erythematosus [79]. The secretion of LL37 facilitated the uptake and recognition of DNA by plasmacytoid dendritic cells. The antimicrobial peptide LL37 was also overexpressed in the lesional psoriatic skins and would participate in the activation of cells of innate immunity [80].

Neutrophils participate in the secretion of inflammatory mediators, including IL- $1 \alpha$, IL- 8 , TNF- $\alpha$, and IFN- $\gamma$ cytokines [81-84]. The interaction of neutrophils and fibroblasts may increase the secretion of IL-8 [85]. In addition, IL-12, expressed on the surface of mononuclear cells, such as epidermal neutrophils, is overexpressed in psoriatic lesions. Although fibroblasts do not secrete IL-12, the fibroblastneutrophil interaction upregulates IL-12 secretion, highlighting the importance and necessity of considering cooperation between the different cells to better understand these interactions. Furthermore, IL-12 promoted the survival and growth of Th1 cells, as well as their differentiation, and inhibited the formation of Th2 cells.

The formation of neutrophil-containing microabscesses would be dependent on IL-1R1. It has been demonstrated in the imiquimod-induced murine model that the signaling of IL-1 via IL-1R1 regulated constitutive and induced chemokine expression in response to imiquimod, involved in the in vivo recruitment of neutrophils. However, the deletion of IL-1R1 did not block the formation of microabscesses, 
implying that other cytokines are involved in their formation [86]. CEACAM-1 expression in superficial keratinocytes found in psoriatic lesions would also contribute to the persistence of neutrophils and to the underlying inflammation in psoriatic patients [87].

Aldara cream modifies the immune response by stimulating the body's defenses that fight certain types of skin affections. The topical application of Aldara in mice deficient in IL-17A, IL-17F, or IL-22 drastically reduced the severity of psoriasis. However, $\gamma \delta$ T cell populations and innate ROR $\gamma \mathrm{t}-$ positive lymphocytes produced large amounts of these inflammatory cytokines and were necessary and sufficient for the formation of psoriatic lesion plaques in this murine model. A reverse ROR $\gamma$ t agonist, developed by Janssen, has demonstrated its efficacy in murine models for psoriasis and inflammatory arthritis. The blockade of the Th17 differentiation led to the decrease of the production of IL-17A by the memory $\mathrm{T}$ cells and reduced the production of IL-17A and IL- 22 by the cells NKT and $\gamma \delta$ [88].

Furthermore, the combined action of mannan-activated macrophages and IL-17A from T cells provoked the infiltration of neutrophils into skin compartments, leading to histopathological features [89].

IL-17F would induce the secretion of IL- 8 by the keratinocytes and would favor the infiltration of neutrophils into the dermis. On the other hand, the blocking of neutrophil infiltration by an anti-IL-8 antibody underlined the importance of the IL-17F/IL-8 axis in the pathophysiology of psoriasis [90].

At last, a treatment with ustekinumab (human monoclonal antibody directed against IL-12 and IL-23p40) or infliximab (monoclonal chimeric antibody directed against TNF), both used to treat psoriasis, in severe psoriatic patients appeared to decrease the activity of neutrophils and monocytes. Indeed, the expression of CD62L, a molecule of cell adhesion, is restored in patients receiving biological therapy, while expressions of CD11b (also called integrin alpha M) and CD66b, another adhesion molecule, were decreased after treatment. Also, the ratio of activated CD14 ${ }^{\text {high }}$ monocytes was normalized in patients receiving therapy [91], stressing once again the importance of these immune cells in psoriasis.

In vivo models have demonstrated the complex but evident interrelationship between different immune cells at the level of psoriatic lesions and provide a better understanding of the influence that cells have on each other and the possible modulating effect of cytokines and chemokines on the functioning of neighboring cells in the local microenvironment (Figure 1).

\section{3D Organotypic Skin Models}

At present, few organotypic models emphasize the importance of macrophages or neutrophils in psoriasis, but the enthusiasm for such models could lead us to make new discoveries in the years to come.

Some models already demonstrated the role of $\mathrm{T}$ cells in the pathogenesis of psoriasis. In the 1990s, transplants of human psoriatic skins in immunodeficient mice [92] and injected with autologous $\mathrm{T}$ cells, from either peripheral blood or the lesion site, indicated that only the latter was able to maintain the psoriatic phenotype in the grafted mice [93]. In 2010, to counter the limitations associated with such models, Guerrero-Aspizua et al. isolated both skin cells-keratinocytes and fibroblasts-and peripheral blood from psoriatic patients and reproduced cutaneous equivalents by bioengineering [94]. These equivalents were then grafted onto immunodeficient mice. The authors indicated that intraepidermal injection of activated human immunocytes induced the formation of psoriatic lesion in the skin model of xenotransplantation. The authors observed that the combination of factors secreted by Th1 cells and cytokines derived from Th17 cells was essential for the complete development of a psoriatic phenotype, emphasizing the importance of $\mathrm{T}$ cells in the pathology.

In 2002, Del Rio and colleagues performed a long-term follow-up of gene-transferred bioengineered artificial human skin based on a fibroblast-containing fibrin dermal substrate orthotopically grafted onto mice [95]. This preclinical approach, considered more clinically relevant and better predictive models of drug efficacy, will certainly identify new therapeutic targets for psoriasis. Moreover, the topical application of nanosomes containing siRNAs inhibiting the expression of hBD-2 in such a mouse model improved the cutaneous phenotype and reduced the number and the size of blood vessels in the dermal compartment [96].

Modeling psoriatic inflammation requires paying close attention to the immune component. Some organotypic 3D models, with no immune component, attempt to mimic psoriatic inflammation. In our lab, we have already demonstrated that the generation of skin equivalents from human psoriatic fibroblasts and keratinocytes produced by the self-assembly method displayed major hallmarks of psoriasis [97]. Also, although the addition of a cytokine cocktail [94, 98-100], or a single protein [101], to mimic psoriatic inflammation has demonstrated some histopathological aspects of psoriasis, it is unlikely that all mediators released by immune cells will be generated with a mixture of a few inflammatory cytokines. Although essential, animal models cannot reflect the etiology of psoriasis or represent the human complexity associated with pathology.

An alternative to animal experimentation is the development of equivalent three-dimensional models generated from human skin cells. These organotypic models, which are rapidly expanding, make it possible, by adding one or more cutaneous components, to dissect the specific role of each cell type present. Conversely, current models, usually with only one immune component, cannot summarize all the cellular and molecular interactions occurring in vivo due to the absence of other components, which are certainly important to the general pathophysiology of psoriasis. Moreover, deletion of an element (macrophages by clodronate liposomes, e.g.) very rarely results in a complete reversion of the phenotype, thus implying that other constituents are involved in the pathology development.

Thus far, too few in vitro three-dimensional models including the main cellular components involved in the pathophysiology of autoimmune diseases, such as psoriasis or atopic dermatitis, are currently being studied to further 
TABLE 2: Observed features in 3D organotypic skin models.

(a)

\begin{tabular}{|c|c|c|c|}
\hline $3 \mathrm{D}$ in vitro models & Components & Support & Observed features \\
\hline $\begin{array}{l}\text { Dezutter-Dambuyant et al. } \\
\text { [102] }\end{array}$ & $\begin{array}{l}\text { Fibroblasts + keratinocytes + } \\
\text { endothelialized cells + CD34- } \\
\text { positive cells }\end{array}$ & $\begin{array}{l}\text { Solid scaffold of bovine collagen, } \\
\text { chitosan and chondroitin 4-6 } \\
\text { sulfate }\end{array}$ & $\begin{array}{l}\text { Differentiation of interstitial } \\
\text { dendritic dells }\end{array}$ \\
\hline Bechetoille et al. [104] & $\begin{array}{c}\text { Fibroblasts }+ \text { dermal macrophages } \\
\text { derived from monocytes }\end{array}$ & $\begin{array}{l}\text { Solid scaffold of bovine collagen, } \\
\text { chitosan and chondroitin 4-6 } \\
\text { sulfate }\end{array}$ & $\begin{array}{l}\text { Display phagocytosis and remain } \\
\text { responsive to LPS }\end{array}$ \\
\hline Chau et al. [103] & $\begin{array}{c}\text { Fibroblasts + keratinocytes + } \\
\text { dendritic cells }\end{array}$ & $\begin{array}{l}\text { Nondegradable microfibre } \\
\text { scaffolds and a cell-laden gel }\end{array}$ & $\begin{array}{l}\text { Able to migrate and remain } \\
\text { responsive to stimulation with skin } \\
\text { sensitizers }\end{array}$ \\
\hline Pageon et al. [106] & $\begin{array}{l}\text { Fibroblasts + keratinocytes }+ \\
\text { monocytes }\end{array}$ & AGE-modified collagen lattices & $\begin{array}{c}\text { Differentiation of CD14+ } \\
\text { monocytes into dendritic cells and } \\
\text { macrophages }\end{array}$ \\
\hline
\end{tabular}

(b) 3D models for psoriasis (without immune cells).

\begin{tabular}{|c|c|c|c|}
\hline $3 \mathrm{D}$ in vitro models & Components & Support & Observed features \\
\hline Barker et al. [111] & $\begin{array}{c}\text { Fibroblasts + keratinocytes isolated from } \\
\text { human lesional skin }\end{array}$ & Collagen gels & Psoriasis-like phenotype \\
\hline Tjabringa et al. [98] & $\begin{array}{c}\text { Healthy keratinocytes }+ \\
\text { de-epidermized dermis }+ \text { cytokines } \\
\text { (IL- } 1 \alpha, \text { TNF- } \alpha \text {, IL-6 and IL-22) }\end{array}$ & De-epidermized dermis & Psoriasis-like phenotype \\
\hline Jean et al. [97] & $\begin{array}{l}\text { Psoriatic fibroblasts + psoriatic } \\
\text { keratinocytes }\end{array}$ & $\begin{array}{l}\text { Fibroblast-derived dermal } \\
\text { matrix }\end{array}$ & Psoriasis-like phenotype \\
\hline $\begin{array}{l}\text { van den Bogaard } \\
\text { et al. [105] }\end{array}$ & $\begin{array}{l}\text { Healthy keratinocytes }+ \text { activated } \\
\text { CD4-positive T cells and } \\
\text { Th1/Th17-polarized T cells }\end{array}$ & $\begin{array}{l}\text { Decellularized deepidermized } \\
\text { dermis }\end{array}$ & Psoriasis-like phenotype \\
\hline
\end{tabular}

understand the role of the microenvironment in maintaining inflammation. The influence of the components on the modulation of the soluble and nonsoluble factors constituting the local lesional microenvironment can be apprehended by the generation of 3D models. However, the difficulty of incorporating immune cells into skin models, along with the complexity involved in modeling a threedimensional environment necessary and sufficient to maintain cell viability and to respect the anatomical arrangement of cells, represents a major challenge.

In 2006, Dezutter-Dambuyant et al. optimized the development of a reconstructed skin model by incorporating hematopoietic progenitor cells in an endothelialized skin equivalent. The team demonstrated that the differentiation of dendritic cell precursors into Langerhans cells depends on the state of differentiation of keratinocyte cells. In this case, the differentiation program of the Langerhans cells started only if keratinocytes were differentiated. Interaction between fibroblasts and keratinocytes in a threedimensional skin model supported the regulation of their own differentiation and also that of anatomically close cells [102].

The encapsulation of dendritic cells in an agarose and fibronectin gel, compartmentalized between a layer of fibroblasts and keratinocytes and treated with dichlorobenzene for 24 hours, makes it possible to study the cellular interactions and mechanisms of skin sensitization [103]. In addition to maintaining their viability and horizontal and vertical migration, dendritic cells appeared to maintain an immature phenotype in the presence of fibronectin, expressed higher levels of endocytic receptors, and had a greater potential to induce $\mathrm{T}$ cell activation.

In 2011, Bechetoille et al. developed a dermal equivalent model of bovine collagen, chitosan, chondroitin sulfate, fibroblasts, and dermal macrophages derived from monocytes [104]. Macrophages, with the "classical" fusiform morphology, expressed CD14, CD163, and DC-SIGN/CD209 markers and produced large amounts of IL-10 in response to LPS, but little TNF. While LPS stimulated immune responses by interacting with the CD14 membrane receptor and induced the secretion of proinflammatory cytokines, such as TNF- $\alpha$, IL-1, and IL-6, a stimulation of LPS macrophages in this in vitro model promoted their antiinflammatory activity.

In 2014, van den Bogaard et. al developed a threedimensional healthy in vitro skin substitute model in which they injected allogeneic healthy $\mathrm{T}$ lymphocytes into the dermal compartment. The authors demonstrated that the polarization of T cells towards a Th1 or Th17 phenotype, then injected in skin substitutes, induced the expression of molecular markers associated with psoriasis, although no hyperproliferation or acanthosis was observed. The inflammatory phenotype thus developed is similar to the psoriatic phenotype observed in human lesional plaques [105]. 
In another context, it has also been demonstrated that the generation of glycated cutaneous equivalents promoted the differentiation of monocytic cells towards a macrophage or dendritic cell phenotype. It would be interesting to characterize the influence of these differentiated cells on the modulation of the secretory profile in glycated substitutes [106] (Table 2).

\section{Future Directions}

The aim of this review was to analyze the importance of immune cells, and more particularly leukocyte cells, as neutrophils and macrophages in the pathophysiology of psoriasis. The emphasis is often on $\mathrm{T}$ cells, yet the influence of other immune cells on lymphocytes and keratinocytes must be better characterized. The specific roles of each cell types must be dissected to better understand the cellular hierarchy established in psoriasis. We also discussed the need to develop new in vitro models with a three-dimensional microenvironment and appropriate and relevant cellular components to better mimic the pathology and improve our understanding of it. Besides, it would also be advantageous to integrate other types of immune cells, such as dendritic cells, into human skin three-dimensional models, given their role in the presentation of antigens to $\mathrm{T}$ lymphocytes. Although there is a great temptation to develop a more complete model including immune, cutaneous, and endothelial cells to better reflect the actors involved in inflammation, it is often difficult to know if an observed effect is due to a single cell type or an interaction between anatomically close cells.

The development of complex three-dimensional models is an important issue for research in pharmacology. Today, most of the available models reproduce only very partially the in vivo situation because their architecture does not consider the complexity of the tissue interfaces and the vascular perfusion. Recently, some companies have begun to develop organs or tissues as relevant tools to repetitively assess the pharmacological action of drugs. For instance, Organovo, based in the United States, commercialized its first liver model in 2014, which incorporates hepatocytes, stellate cells, and endothelial cells, printed in a matrix. This model would be more discriminating than $2 \mathrm{D}$ cultures and would make it possible to mimic a patient's response to a drug [107]. It would be wise to focus on these in vitro models, given the ethical and financial constraints associated with the use of animal models.

Recently, new antipsoriatic therapies have emerged, such as apremilast (Otezla, Celgene), a phosphodiesterase 4 (PDE4) inhibitor, which is also the first oral antiinflammatory treatment for psoriasis in more than 20 years. PDE4 inhibition would also be a potential target for systemic sclerosis, as its blockage decreased dermal fibrosis through the downregulation of profibrotic mediators from M2 macrophages [108].

Other promising drugs are currently being tested in phase III in the US, specifically targeting the inhibition of phospholipase A2 (PLA2), which controls the biosynthesis of inflammatory mediators, such as leukotrienes and prostaglandins. Other biological agents, such as etanercept (Enbrel,
Amgen), infliximab (Remicade, Merck \& Co./Janssen Biotech), and adalimumab (Humira, AbbVie), which are tumor necrosis factor (TNF) antagonists, are more commonly administered, although some side effects are frequently observed in patients (>10\%): viral infection, dyspnea, migraine, and nausea. Since 2009, biological agents against psoriasis targeting IL-12, IL-17, and IL-23, cytokines that play a key role in inflammatory and immune responses, have been licensed on the market. Ustekinumab was the first drug specifically designed to suppress inflammation by targeting the signaling pathway of the cytokine family of interleukin12 (IL-12) and interleukin-23 (IL-23).

Another therapeutic approach, the encapsulation of antipsoriatic agents in nanoparticles [109, 110], is currently under study with the aim of improving the efficacy, safety, and compliance of potential agents.

Advances in psoriasis research continue to lead to new therapeutic strategies that promise better management of this complex disease in the future. For sure, development of in vitro models and mouse models will help to revolutionize the care of psoriasis in the years to come.

\section{Conflicts of Interest}

The authors declare that there is no conflict of interest regarding the publication of this review.

\section{Authors' Contributions}

Isabelle Lorthois wrote the manuscript, which has been corrected and revised by Daniel Asselineau, Nathalie Seyler, and Roxane Pouliot.

\section{References}

[1] F. O. Nestle, D. H. Kaplan, and J. Barker, "Psoriasis," The New England Journal of Medicine, vol. 361, no. 5, pp. 496-509, 2009.

[2] C. E. Griffiths and J. N. Barker, "Pathogenesis and clinical features of psoriasis," The Lancet, vol. 370, no. 9583, pp. 263-271, 2007.

[3] B. A. Bernard, S. M. Robinson, S. Vandaele, J. N. Mansbridge, and M. Darmon, "Abnormal maturation pathway of keratinocytes in psoriatic skin," The British Journal of Dermatology, vol. 112, no. 6, pp. 647-653, 1985.

[4] B. A. Bernard, A. Reano, Y. M. Darmon, and J. Thivolet, "Precocious appearance of involucrin and epidermal transglutaminase during differentiation of psoriatic skin," The British Journal of Dermatology, vol. 114, no. 3, pp. 279-283, 1986.

[5] B. A. Bernard, D. Asselineau, L. Schaffar-Deshayes, and M. Y. Darmon, "Abnormal sequence of expression of differentiation markers in psoriatic epidermis: inversion of two steps in the differentiation program?," The Journal of Investigative Dermatology, vol. 90, no. 6, pp. 801-805, 1988.

[6] F. Bernerd, T. Magnaldo, and M. Darmon, "Delayed onset of epidermal differentiation in psoriasis," The Journal of Investigative Dermatology, vol. 98, no. 6, pp. 902-910, 1992. 
[7] M. Detmar, L. F. Brown, K. P. Claffey et al., "Overexpression of vascular permeability factor/vascular endothelial growth factor and its receptors in psoriasis," The Journal of Experimental Medicine, vol. 180, no. 3, pp. 1141-1146, 1994.

[8] M. Verschoore, C. Kowalewski, M. J. Chorzelska, B. A. Bernard, and Y. M. Darmon, "Intraepidermal leakage of plasma proteins after tape stripping of normal skin and uninvolved psoriatic skin," The British Journal of Dermatology, vol. 122, no. 3, pp. 391-397, 1990.

[9] Meier TO, L. Kovacicova, R. Huggenberger, A. A. Navarini, G. Gitzelmann, and B. R. Amann-Vesti, "Increased permeability of cutaneous lymphatic capillaries and enhanced blood flow in psoriatic plaques," Dermatology, vol. 227, no. 2, pp. 118-125, 2013.

[10] D. Parent, B. A. Bernard, C. Desbas, M. Heenen, and M. Y. Darmon, "Spreading of psoriatic plaques: alteration of epidermal differentiation precedes capillary leakiness and anomalies in vascular morphology," The Journal of Investigative Dermatology, vol. 95, no. 3, pp. 333-340, 1990.

[11] A. Menter, A. Gottlieb, S. R. Feldman et al., "Guidelines of care for the management of psoriasis and psoriatic arthritis: section 1. Overview of psoriasis and guidelines of care for the treatment of psoriasis with biologics," Journal of the American Academy of Dermatology, vol. 58, no. 5, pp. 826-850, 2008.

[12] R. C. Trembath, R. L. Clough, J. L. Rosbotham et al., "Identification of a major susceptibility locus on chromosome $6 \mathrm{p}$ and evidence for further disease loci revealed by a two stage genome-wide search in psoriasis," Human Molecular Genetics, vol. 6, no. 5, pp. 813-820, 1997.

[13] R. P. Nair, T. Henseler, S. Jenisch et al., "Evidence for two psoriasis susceptibility loci (HLA and $17 \mathrm{q}$ ) and two novel candidate regions ( $16 \mathrm{q}$ and $20 \mathrm{p}$ ) by genome-wide scan," Human Molecular Genetics, vol. 6, no. 8, pp. 1349-1356, 1997.

[14] A. D. Burden, S. Javed, M. Bailey, M. Hodgins, M. Connor, and D. Tillman, "Genetics of psoriasis: paternal inheritance and a locus on chromosome 6p," The Journal of Investigative Dermatology, vol. 110, no. 6, pp. 958-960, 1998.

[15] J. E. Gudjonsson, A. Johnston, H. Sigmundsdottir, and H. Valdimarsson, "Immunopathogenic mechanisms in psoriasis," Clinical and Experimental Immunology, vol. 135, no. 1, pp. 1-8, 2004.

[16] J. T. Elder, R. P. Nair, S. W. Guo, T. Henseler, E. Christophers, and J. J. Voorhees, "The genetics of psoriasis," Archives of Dermatology, vol. 130, no. 2, pp. 216-224, 1994.

[17] J. Jarczak, E. M. Kosciuczuk, P. Lisowski et al., "Defensins: natural component of human innate immunity," Human Immunology, vol. 74, no. 9, pp. 1069-1079, 2013.

[18] E. J. Hollox, U. Huffmeier, P. L. Zeeuwen et al., "Psoriasis is associated with increased $\beta$-defensin genomic copy number," Nature Genetics, vol. 40, no. 1, pp. 23-25, 2008.

[19] L. C. Tsoi, S. L. Spain, J. Knight et al., "Identification of 15 new psoriasis susceptibility loci highlights the role of innate immunity," Nature Genetics, vol. 44, no. 12, pp. 1341-1348, 2012.

[20] S. P. Jariwala, "The role of dendritic cells in the immunopathogenesis of psoriasis," Archives of Dermatological Research, vol. 299, no. 8, pp. 359-366, 2007.

[21] R. Lande, J. Gregorio, V. Facchinetti et al., "Plasmacytoid dendritic cells sense self-DNA coupled with antimicrobial peptide," Nature, vol. 449, no. 7162, pp. 564-569, 2007.
[22] B. J. Nickoloff and F. O. Nestle, "Recent insights into the immunopathogenesis of psoriasis provide new therapeutic opportunities," The Journal of Clinical Investigation, vol. 113, no. 12, pp. 1664-1675, 2004

[23] M. A. Lowes, A. M. Bowcock, and J. G. Krueger, "Pathogenesis and therapy of psoriasis," Nature, vol. 445, no. 7130, pp. 866-873, 2007.

[24] G. Arango Duque and A. Descoteaux, "Macrophage cytokines: involvement in immunity and infectious diseases," Frontiers in Immunology, vol. 5, p. 491, 2014.

[25] M. L. Karnovsky, "Metchnikoff in Messina: a century of studies on phagocytosis," The New England Journal of Medicine, vol. 304, no. 19, pp. 1178-1180, 1981.

[26] T. M. Doherty, "T-cell regulation of macrophage function," Current Opinion in Immunology, vol. 7, no. 3, pp. 400-404, 1995.

[27] R. Mirza, L. A. DiPietro, and T. J. Koh, "Selective and specific macrophage ablation is detrimental to wound healing in mice," The American Journal of Pathology, vol. 175, no. 6, pp. 2454-2462, 2009.

[28] S. J. Leibovich and R. Ross, "The role of the macrophage in wound repair. A study with hydrocortisone and antimacrophage serum," The American Journal of Pathology, vol. 78, no. 1, pp. 71-100, 1975.

[29] T. Lucas, A. Waisman, R. Ranjan et al., "Differential roles of macrophages in diverse phases of skin repair," Journal of Immunology, vol. 184, no. 7, pp. 3964-3977, 2010.

[30] M. S. Koh, B. B. Majewski, and E. L. Rhodes, "Increased macrophage activity in psoriasis," Acta Dermato-Venereologica, vol. 65, no. 3, pp. 194-198, 1985.

[31] J. Fuentes-Duculan, M. Suarez-Farinas, L. C. Zaba et al., "A subpopulation of CD163-positive macrophages is classically activated in psoriasis," The Journal of Investigative Dermatology, vol. 130, no. 10, pp. 2412-2422, 2010.

[32] L. S. Taams, L. W. Poulter, M. H. Rustin, and A. N. Akbar, "Phenotypic analysis of IL-10-treated macrophages using the monoclonal antibodies RFD1 and RFD7," Pathobiology, vol. 67, no. 5-6, pp. 249-252, 2000.

[33] K. Micklem, E. Rigney, J. Cordell et al., "A human macrophage-associated antigen (CD68) detected by six different monoclonal antibodies," British Journal of Haematology, vol. 73, no. 1, pp. 6-11, 1989.

[34] K. Weber-Matthiesen and W. Sterry, "Organization of the monocyte/macrophage system of normal human skin," The Journal of Investigative Dermatology, vol. 95, no. 1, pp. 83-89, 1990.

[35] B. K. Min, K. Suk, and W. H. Lee, "Stimulation of CD107 affects LPS-induced cytokine secretion and cellular adhesion through the ERK signaling pathway in the human macrophage-like cell line, THP-1," Cellular Immunology, vol. 281, no. 2, pp. 122-128, 2013.

[36] E. L. Eskelinen, "Roles of LAMP-1 and LAMP-2 in lysosome biogenesis and autophagy," Molecular Aspects of Medicine, vol. 27, no. 5-6, pp. 495-502, 2006.

[37] O. Elomaa, M. Kangas, C. Sahlberg et al., "Cloning of a novel bacteria-binding receptor structurally related to scavenger receptors and expressed in a subset of macrophages," Cell, vol. 80, no. 4, pp. 603-609, 1995.

[38] J. Kzhyshkowska, "Multifunctional receptor stabilin-1 in homeostasis and disease," Scientific World Journal, vol. 10, pp. 2039-2053, 2010. 
[39] S. Goerdt, R. Bhardwaj, and C. Sorg, "Inducible expression of MS-1 high-molecular-weight protein by endothelial cells of continuous origin and by dendritic cells/macrophages in vivo and in vitro," The American Journal of Pathology, vol. 142, no. 5, pp. 1409-1422, 1993.

[40] V. Kodelja and S. Goerdt, "Dissection of macrophage differentiation pathways in cutaneous macrophage disorders and in vitro," Experimental Dermatology, vol. 3, no. 6, pp. 257-268, 1994.

[41] M. Egawa, K. Mukai, S. Yoshikawa et al., "Inflammatory monocytes recruited to allergic skin acquire an antiinflammatory M2 phenotype via basophil-derived interleukin-4," Immunity, vol. 38, no. 3, pp. 570-80, 2013.

[42] C. Vestergaard, H. Just, J. Baumgartner Nielsen, K. ThestrupPedersen, and M. Deleuran, "Expression of CCR2 on monocytes and macrophages in chronically inflamed skin in atopic dermatitis and psoriasis," Acta Dermato-Venereologica, vol. 84, no. 5, pp. 353-358, 2004.

[43] A. Gratchev, J. Kzhyshkowska, K. Kothe et al., "Mphi1 and Mphi2 can be re-polarized by Th2 or Th1 cytokines, respectively, and respond to exogenous danger signals," Immunobiology, vol. 211, no. 6-8, pp. 473-486, 2006.

[44] H. Wang, T. Peters, D. Kess et al., "Activated macrophages are essential in a murine model for T cell-mediated chronic psoriasiform skin inflammation," The Journal of Clinical Investigation, vol. 116, no. 8, pp. 2105-2114, 2006.

[45] A. Stratis, M. Pasparakis, R. A. Rupec et al., "Pathogenic role for skin macrophages in a mouse model of keratinocyteinduced psoriasis-like skin inflammation," The Journal of Clinical Investigation, vol. 116, no. 8, pp. 2094-2104, 2006.

[46] R. A. Clark and T. S. Kupper, "Misbehaving macrophages in the pathogenesis of psoriasis," The Journal of Clinical Investigation, vol. 116, no. 8, pp. 2084-2087, 2006.

[47] S. Morimura, T. Oka, M. Sugaya, and S. Sato, "CX3CR1 deficiency attenuates imiquimod-induced psoriasis-like skin inflammation with decreased M1 macrophages," Journal of Dermatological Science, vol. 82, no. 3, pp. 175-188, 2016.

[48] J. A. Wolfram, D. Diaconu, D. A. Hatala et al., "Keratinocyte but not endothelial cell-specific overexpression of Tie2 leads to the development of psoriasis," The American Journal of Pathology, vol. 174, no. 4, pp. 1443-1458, 2009.

[49] N. L. Ward, C. M. Loyd, J. A. Wolfram, D. Diaconu, C. M. Michaels, and T. S. McCormick, "Depletion of antigenpresenting cells by clodronate liposomes reverses the psoriatic skin phenotype in KC-Tie2 mice," The British Journal of Dermatology, vol. 164, no. 4, pp. 750-758, 2011.

[50] D. Terhorst, R. Chelbi, C. Wohn et al., "Dynamics and transcriptomics of skin dendritic cells and macrophages in an imiquimod-induced, biphasic mouse model of psoriasis," Journal of Immunology, vol. 195, no. 10, pp. 4953-4961, 2015.

[51] A. B. Wysocki, "Skin anatomy, physiology, and pathophysiology," The Nursing Clinics of North America, vol. 34, no. 4, pp. 777-797, 1999.

[52] J. Kanitakis, "Anatomy, histology and immunohistochemistry of normal human skin," European Journal of Dermatology, vol. 12, no. 4, pp. 390-399, 2002.

[53] E. Glitzner, A. Korosec, P. M. Brunner et al., "Specific roles for dendritic cell subsets during initiation and progression of psoriasis," EMBO Molecular Medicine, vol. 6, no. 10, pp. 1312-1327, 2014.
[54] R. Leite Dantas, D. Masemann, T. Schied et al., "Macrophagemediated psoriasis can be suppressed by regulatory $\mathrm{T}$ lymphocytes," The Journal of Pathology, vol. 240, no. 3, pp. 366-377, 2016.

[55] J. Zhang, Y. Lin, C. Li et al., "IL-35 decelerates the inflammatory process by regulating inflammatory cytokine secretion and M1/M2 macrophage ratio in psoriasis," Journal of Immunology, vol. 197, no. 6, pp. 2131-2144, 2016.

[56] X. Teng, Z. Hu, X. Wei et al., "IL-37 ameliorates the inflammatory process in psoriasis by suppressing proinflammatory cytokine production," Journal of Immunology, vol. 192, no. 4, pp. 1815-1823, 2014.

[57] M. F. Nold, C. A. Nold-Petry, J. A. Zepp, B. E. Palmer, P. Bufler, and C. A. Dinarello, "IL-37 is a fundamental inhibitor of innate immunity," Nature Immunology, vol. 11, no. 11, pp. 1014-1022, 2010.

[58] E. Kolaczkowska and P. Kubes, "Neutrophil recruitment and function in health and inflammation," Nature Reviews. Immunology, vol. 13, no. 3, pp. 159-175, 2013.

[59] G. B. Segel, M. W. Halterman, and M. A. Lichtman, "The paradox of the neutrophil's role in tissue injury," Journal of Leukocyte Biology, vol. 89, no. 3, pp. 359-372, 2011.

[60] B. G. Yipp and P. Kubes, "NETosis: how vital is it?," Blood, vol. 122, no. 16, pp. 2784-2794, 2013.

[61] M. Schon, D. Denzer, R. C. Kubitza, T. Ruzicka, and M. P. Schon, "Critical role of neutrophils for the generation of psoriasiform skin lesions in flaky skin mice," The Journal of Investigative Dermatology, vol. 114, no. 5, pp. 976-983, 2000.

[62] P. Peveri, A. Walz, B. Dewald, and M. Baggiolini, "A novel neutrophil-activating factor produced by human mononuclear phagocytes," The Journal of Experimental Medicine, vol. 167, no. 5, pp. 1547-1559, 1988.

[63] B. Moser, C. Schumacher, V. von Tscharner, I. Clark-Lewis, and M. Baggiolini, "Neutrophil-activating peptide 2 and gro/melanoma growth-stimulatory activity interact with neutrophil-activating peptide 1 /interleukin 8 receptors on human neutrophils," The Journal of Biological Chemistry, vol. 266, no. 16, pp. 10666-10671, 1991.

[64] P. V. Afonso, M. Janka-Junttila, Y. J. Lee et al., "LTB4 is a signal-relay molecule during neutrophil chemotaxis," Developmental Cell, vol. 22, no. 5, pp. 1079-1091, 2012.

[65] E. S. Van Amersfoort, T. J. Van Berkel, and J. Kuiper, "Receptors, mediators, and mechanisms involved in bacterial sepsis and septic shock," Clinical Microbiology Reviews, vol. 16, no. 3, pp. 379-414, 2003.

[66] O. Chertov, D. F. Michiel, L. Xu et al., "Identification of defensin-1, defensin-2, and CAP37/azurocidin as T-cell chemoattractant proteins released from interleukin-8-stimulated neutrophils," The Journal of Biological Chemistry, vol. 271, no. 6, pp. 2935-2940, 1996.

[67] S. Ikeda, H. Takahashi, Y. Suga et al., “Therapeutic depletion of myeloid lineage leukocytes in patients with generalized pustular psoriasis indicates a major role for neutrophils in the immunopathogenesis of psoriasis," Journal of the American Academy of Dermatology, vol. 68, no. 4, pp. 609-617, 2013.

[68] P. C. Res, G. Piskin, O. J. de Boer et al., "Overrepresentation of IL-17A and IL-22 producing CD8 T cells in lesional skin suggests their involvement in the pathogenesis of psoriasis," PLoS One, vol. 5, no. 11, article e14108, 2010. 
[69] R. R. Keijsers, A. G. Hendriks, P. E. van Erp et al., "In vivo induction of cutaneous inflammation results in the accumulation of extracellular trap-forming neutrophils expressing ROR $\gamma \mathrm{t}$ and IL-17," The Journal of Investigative Dermatology, vol. 134, no. 5, pp. 1276-1284, 2014.

[70] K. Reich, K. A. Papp, R. T. Matheson et al., "Evidence that a neutrophil-keratinocyte crosstalk is an early target of IL-17A inhibition in psoriasis," Experimental Dermatology, vol. 24, no. 7, pp. 529-535, 2015.

[71] A. M. Lin, C. J. Rubin, R. Khandpur et al., "Mast cells and neutrophils release IL-17 through extracellular trap formation in psoriasis," Journal of Immunology, vol. 187, no. 1, pp. 490-500, 2011.

[72] H. Sumida, K. Yanagida, Y. Kita et al., "Interplay between CXCR2 and BLT1 facilitates neutrophil infiltration and resultant keratinocyte activation in a murine model of imiquimod-induced psoriasis," Journal of Immunology, vol. 192, no. 9, pp. 4361-4369, 2014.

[73] L. Li, L. Huang, A. L. Vergis et al., "IL-17 produced by neutrophils regulates IFN- $\gamma$-mediated neutrophil migration in mouse kidney ischemia-reperfusion injury," The Journal of Clinical Investigation, vol. 120, no. 1, pp. 331-342, 2010.

[74] S. C. Liang, X. Y. Tan, D. P. Luxenberg et al., "Interleukin (IL)-22 and IL-17 are coexpressed by Th17 cells and cooperatively enhance expression of antimicrobial peptides," The Journal of Experimental Medicine, vol. 203, no. 10, pp. 2271-2279, 2006.

[75] K. E. Nograles, L. C. Zaba, E. Guttman-Yassky et al., "Th17 cytokines interleukin (IL)-17 and IL-22 modulate distinct inflammatory and keratinocyte-response pathways," The British Journal of Dermatology, vol. 159, no. 5, pp. 1092-1102, 2008.

[76] M. Peric, S. Koglin, S. M. Kim et al., "IL-17A enhances vitamin D3-induced expression of cathelicidin antimicrobial peptide in human keratinocytes," Journal of Immunology, vol. 181, no. 12, pp. 8504-8512, 2008.

[77] K. El Malki, S. H. Karbach, J. Huppert et al., “An alternative pathway of imiquimod-induced psoriasis-like skin inflammation in the absence of interleukin-17 receptor a signaling," The Journal of Investigative Dermatology, vol. 133, no. 2, pp. 441-451, 2013.

[78] A. L. Croxford, S. Karbach, F. C. Kurschus et al., "IL-6 regulates neutrophil microabscess formation in IL-17A-driven psoriasiform lesions," The Journal of Investigative Dermatology, vol. 134, no. 3, pp. 728-735, 2014.

[79] G. S. Garcia-Romo, S. Caielli, B. Vega et al., "Netting neutrophils are major inducers of type I IFN production in pediatric systemic lupus erythematosus," Science Translational Medicine, vol. 3, no. 73, p. 73ra20, 2011.

[80] R. Lande, E. Botti, C. Jandus et al., "The antimicrobial peptide LL37 is a T-cell autoantigen in psoriasis," Nature Communications, vol. 5, p. 5621, 2014.

[81] N. A. Cicco, A. Lindemann, J. Content et al., "Inducible production of interleukin- 6 by human polymorphonuclear neutrophils: role of granulocyte-macrophage colony-stimulating factor and tumor necrosis factor-alpha," Blood, vol. 75, no. 10, pp. 2049-2052, 1990.

[82] D. B. Dubravec, D. R. Spriggs, J. A. Mannick, and M. L. Rodrick, "Circulating human peripheral blood granulocytes synthesize and secrete tumor necrosis factor alpha," Proceedings of the National Academy of Sciences, vol. 87, no. 17, pp. 6758-6761, 1990.
[83] E. J. Gosselin, K. Wardwell, W. F. Rigby, and P. M. Guyre, "Induction of MHC class II on human polymorphonuclear neutrophils by granulocyte/macrophage colony-stimulating factor, IFN-gamma, and IL-3," Journal of Immunology, vol. 151, no. 3, pp. 1482-1490, 1993.

[84] A. Matsukawa and M. Yoshinaga, "Neutrophils as a source of cytokines in inflammation," Histology and Histopathology, vol. 14, no. 2, pp. 511-516, 1999.

[85] E. Glowacka, P. Lewkowicz, H. Rotsztejn, and A. Zalewska, "IL-8, IL-12 and IL-10 cytokines generation by neutrophils, fibroblasts and neutrophils- fibroblasts interaction in psoriasis," Advances in Medical Sciences, vol. 55, no. 2, pp. 254-260, 2010.

[86] M. Uribe-Herranz, L. H. Lian, K. M. Hooper, K. A. Milora, and L. E. Jensen, “IL-1R1 signaling facilitates Munro’s microabscess formation in psoriasiform imiquimod-induced skin inflammation," The Journal of Investigative Dermatology, vol. 133, no. 6, pp. 1541-1549, 2013.

[87] M. Rahmoun, J. P. Moles, N. Pedretti et al., "Cytokineinduced CEACAM1 expression on keratinocytes is characteristic for psoriatic skin and contributes to a prolonged lifespan of neutrophils," The Journal of Investigative Dermatology, vol. 129, no. 3, pp. 671-681, 2009.

[88] X. Xue, P. Soroosh, A. De Leon-Tabaldo et al., "Pharmacologic modulation of ROR $\gamma \mathrm{t}$ translates to efficacy in preclinical and translational models of psoriasis and inflammatory arthritis," Scientific Reports, vol. 6, article 37977, 2016.

[89] I. Khmaladze, T. Kelkka, S. Guerard et al., "Mannan induces ROS-regulated, IL-17A-dependent psoriasis arthritis-like disease in mice," Proceedings of the National Academy of Sciences, vol. 111, no. 35, pp. E3669-E3678, 2014.

[90] H. Watanabe, M. Kawaguchi, S. Fujishima et al., "Functional characterization of IL-17F as a selective neutrophil attractant in psoriasis," The Journal of Investigative Dermatology, vol. 129, no. 3, pp. 650-656, 2009.

[91] K. Yamanaka, Y. Umezawa, A. Yamagiwa et al., "Biologic therapy improves psoriasis by decreasing the activity of monocytes and neutrophils," The Journal of Dermatology, vol. 41, no. 8, pp. 679-685, 2014.

[92] B. J. Nickoloff, S. L. Kunkel, M. Burdick, and R. M. Strieter, "Severe combined immunodeficiency mouse and human psoriatic skin chimeras. Validation of a new animal model," The American Journal of Pathology, vol. 146, no. 3, pp. 580-588, 1995.

[93] A. Gilhar, M. David, Y. Ullmann, T. Berkutski, and R. S. Kalish, "T-lymphocyte dependence of psoriatic pathology in human psoriatic skin grafted to SCID mice," The Journal of Investigative Dermatology, vol. 109, no. 3, pp. 283-288, 1997.

[94] S. Guerrero-Aspizua, M. Garcia, R. Murillas et al., "Development of a bioengineered skin-humanized mouse model for psoriasis: dissecting epidermal-lymphocyte interacting pathways," The American Journal of Pathology, vol. 177, no. 6, pp. 3112-3124, 2010.

[95] M. Del Rio, F. Larcher, F. Serrano et al., "A preclinical model for the analysis of genetically modified human skin in vivo," Human Gene Therapy, vol. 13, no. 8, pp. 959-968, 2002.

[96] S. Bracke, M. Carretero, S. Guerrero-Aspizua et al., "Targeted silencing of DEFB4 in a bioengineered skin-humanized mouse model for psoriasis: development of siRNA 
SECosome-based novel therapies," Experimental Dermatology, vol. 23, no. 3, pp. 199-201, 2014.

[97] J. Jean, M. Lapointe, J. Soucy, and R. Pouliot, "Development of an in vitro psoriatic skin model by tissue engineering," Journal of Dermatological Science, vol. 53, no. 1, pp. 19-25, 2009.

[98] G. Tjabringa, M. Bergers, D. van Rens, R. de Boer, E. Lamme, and J. Schalkwijk, "Development and validation of human psoriatic skin equivalents," The American Journal of Pathology, vol. 173, no. 3, pp. 815-823, 2008.

[99] C. Pouliot-Berube, K. Zaniolo, S. L. Guerin, and R. Pouliot, "Tissue-engineered human psoriatic skin supplemented with cytokines as an in vitro model to study plaque psoriasis," Regenerative Medicine, vol. 11, no. 6, pp. 545-557, 2016.

[100] M. Carretero, S. Guerrero-Aspizua, N. Illera et al., "Differential features between chronic skin inflammatory diseases revealed in skin-humanized psoriasis and atopic dermatitis mouse models," The Journal of Investigative Dermatology, vol. 136, no. 1, pp. 136-145, 2016.

[101] A. Gazel, M. Rosdy, B. Bertino, C. Tornier, F. Sahuc, and M. Blumenberg, "A characteristic subset of psoriasisassociated genes is induced by oncostatin-M in reconstituted epidermis," The Journal of Investigative Dermatology, vol. 126, no. 12, pp. 2647-2657, 2006.

[102] C. Dezutter-Dambuyant, A. Black, N. Bechetoille et al., "Evolutive skin reconstructions: from the dermal collagenglycosaminoglycan- chitosane substrate to an immunocompetent reconstructed skin," Bio-medical Materials and Engineering, vol. 16, Supplement 4, pp. S85-S94, 2006.

[103] D. Y. Chau, C. Johnson, S. MacNeil, J. W. Haycock, and A. M. Ghaemmaghami, "The development of a 3D immunocompetent model of human skin," Biofabrication, vol. 5, no. 3, article 035011, 2013.

[104] N. Bechetoille, H. Vachon, A. Gaydon et al., "A new organotypic model containing dermal-type macrophages," Experimental Dermatology, vol. 20, no. 12, pp. 10351037, 2011.

[105] E. H. van den Bogaard, G. S. Tjabringa, I. Joosten et al., "Crosstalk between keratinocytes and $\mathrm{T}$ cells in a 3D microenvironment: a model to study inflammatory skin diseases," The Journal of Investigative Dermatology, vol. 134, no. 3, pp. 719-727, 2014.

[106] H. Pageon, H. Zucchi, F. Rousset, S. Girardeau-Hubert, E. Tancrede, and D. Asselineau, "Glycation stimulates cutaneous monocyte differentiation in reconstructed skin in vitro," Mechanisms of Ageing and Development, vol. 162, pp. 18-26, 2017.

[107] D. G. Nguyen, J. Funk, J. B. Robbins et al., "Bioprinted 3D primary liver tissues allow assessment of organ-level response to clinical drug induced toxicity in vitro," PLoS One, vol. 11, no. 7, article e0158674, 2016.

[108] C. Maier, A. Ramming, C. Bergmann et al., "Inhibition of phosphodiesterase 4 (PDE4) reduces dermal fibrosis by interfering with the release of interleukin-6 from M2 macrophages," Annals of the Rheumatic Diseases, vol. 76, 2017.

[109] H. Bessar, I. Venditti, L. Benassi et al., "Functionalized gold nanoparticles for topical delivery of methotrexate for the possible treatment of psoriasis," Colloids and Surfaces. B, Biointerfaces, vol. 141, pp. 141-147, 2016.
[110] T. Ramezanli, B. E. Kilfoyle, Z. Zhang, and B. B. MichniakKohn, "Polymeric nanospheres for topical delivery of vitamin D3," International Journal of Pharmaceutics, vol. 516, no. 1-2, pp. 196-203, 2017.

[111] C. L. Barker, M. T. McHale, A. K. Gillies et al., "The development and characterization of an in vitro model of psoriasis," Journal of Investigative Dermatology, vol. 123, no. 5, pp. 892-901, 2004. 


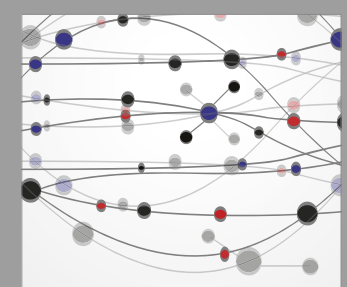

The Scientific World Journal
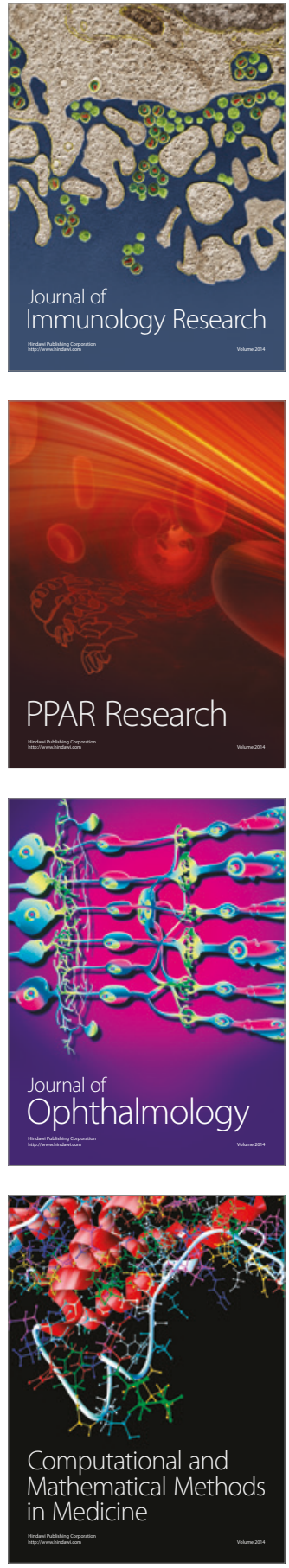

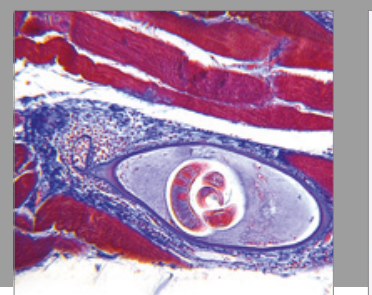

Gastroenterology Research and Practice
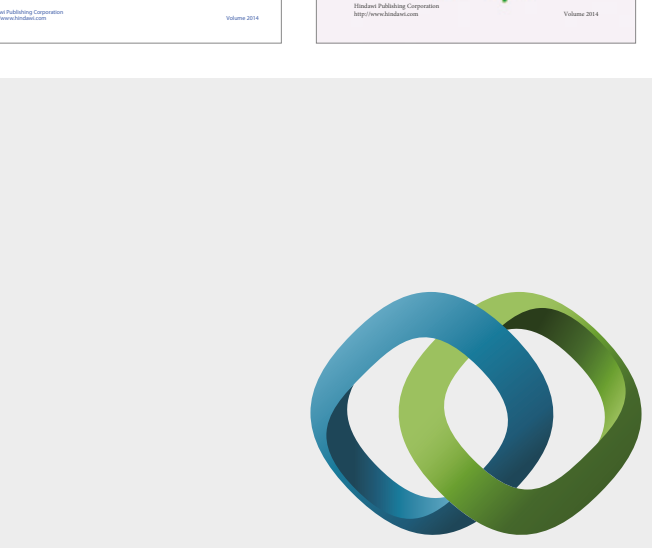

\section{Hindawi}

Submit your manuscripts at

https://www.hindawi.com
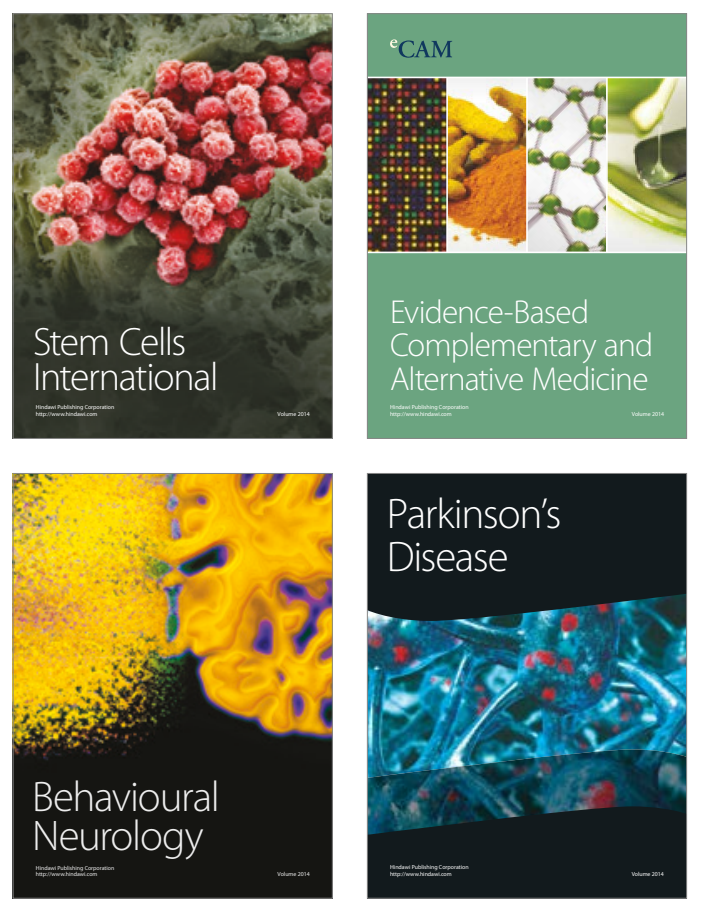
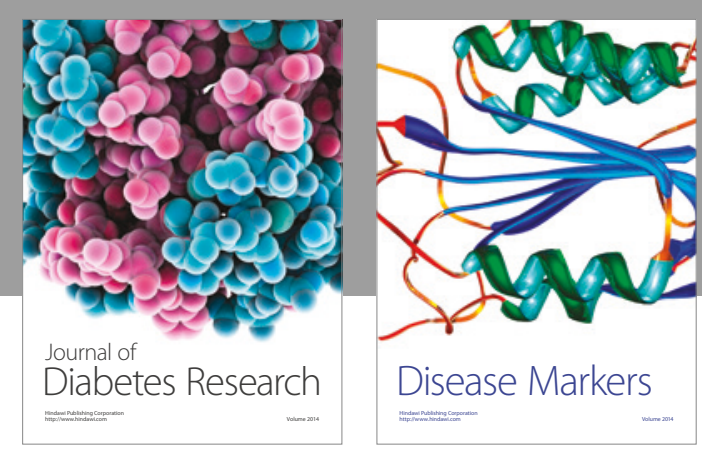

Disease Markers
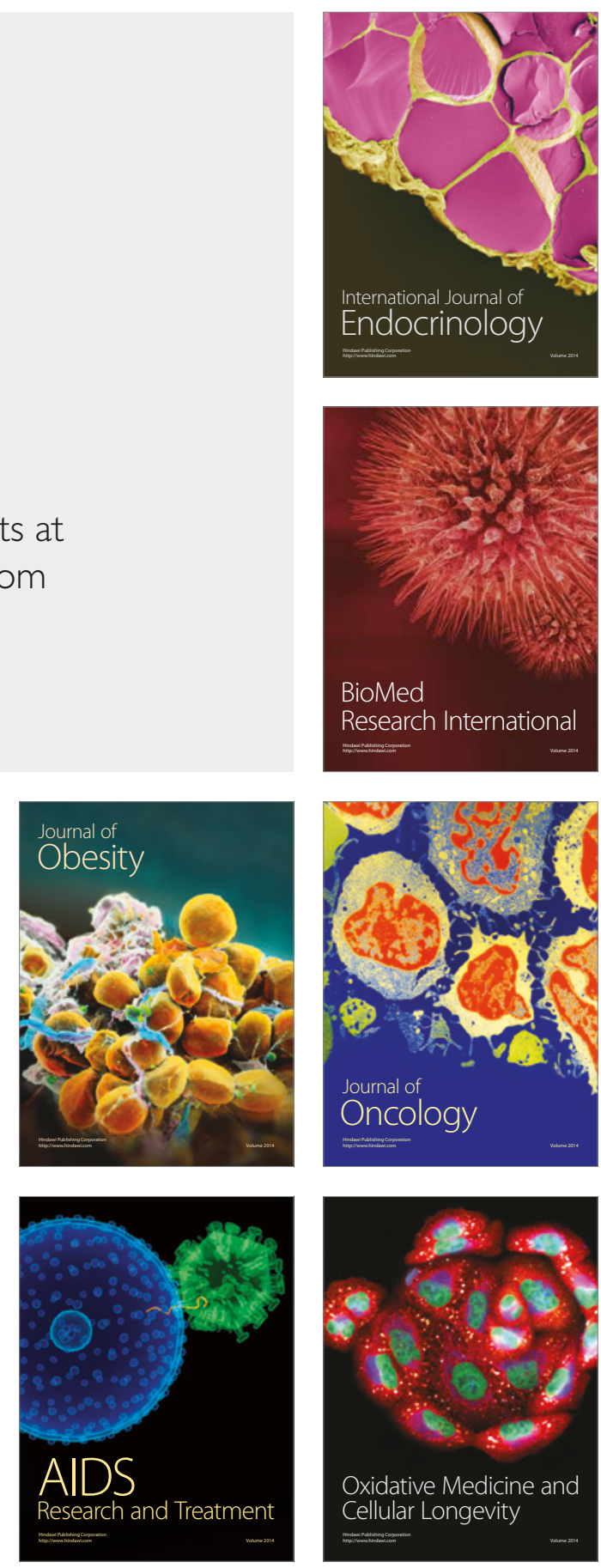